\title{
ANÁLISE FLORÍSTICA DO COMPONENTE ARBÓREO DO PARQUE MUNICIPAL JOSEPHA COELHO, PETROLINA - PE
}

\author{
FLORISTIC ANALYSIS OF ARBOREAL COMPONENT OF JOSEPHA COELHO \\ MUNICIPAL PARK, PETROLINA - PE
}

Danilo Diego de Souza ${ }^{1}$

\begin{abstract}
RESUMO
Os parques urbanos são áreas verdes que destacam-se como pontos turísticos, paisagísticos e ambientais. O presente trabalho objetivou, por meio de levantamento florístico, verificar a diversidade e composição de espécies arbóreas do Parque Municipal Josepha Coelho, Petrolina-PE. Para tal, foi feito um levantamento quantitativo por meio de observação em campo, no qual foram identificadas as espécies, como também avaliados o número de espécies nativas do Brasil e exóticas. Na análise da vegetação arbórea do parque municipal constatou-se que sua composição florística é formada por 757 indivíduos adultos distribuídos em 28 espécies, pertencentes a 10 famílias botânicas. O levantamento indicou ainda que $50,59 \%$ das espécies eram nativas e $49,41 \%$ exóticas, o que significa que o número de espécies exóticas é expressivo, com destaque para Azadirachta indica A. Juss (neem), perfazendo 16,64\% do total de espécies. O excesso de espécies exóticas causadoras de impactos ambientais na arborização retrata uma ausência de preocupação com a conservação da vegetação nativa, como também 0 desconhecimento de tais impactos ambientais. Sugere-se a substituição gradual de $A$. indica por espécies nativas da Caatinga, com intuito de promover a diversidade adequada no local.
\end{abstract}

Palavras-chave: Levantamento florístico; Áreas verdes; Composição de espécies.

\begin{abstract}
Urban parks are green areas that stand out as tourist, landscaping and environmental points. The present study aimed, through a floristic survey, to verify the diversity and composition of arboreal species of Josepha Coelho Municipal Park, Petrolina-PE. For this, a quantitative survey was carried out through observation in the field, in which species were identified, as well as the number of native to Brazil and exotic species. In the arboreal vegetation's analysis of the municipal park was verified that its floristic composition is formed by 757 adult individuals distributed in 28 species, belonging to 10 botanical families. The survey also indicated that $50.59 \%$ of the species were native and $49.41 \%$ exotic, which means that the number of exotic species is expressive, especially Azadirachta indica A. Juss (neem), accounting for $16.64 \%$ of the total of species. The excess of exotic species that cause environmental impacts in the afforestation shows an absence of concern with the conservation of the native vegetation, as well as the lack of knowledge of such environmental impacts. It is suggested the gradual substitution of $A$. indica by native species of Caatinga, in order to promote adequate diversity in the place.
\end{abstract}

Keywords: Floristic survey; Green areas; Species composition.

Recebido em 15.09.2017 e aceito em 15.01.2018

1 Biólogo (UPE). Mestre em Botânica (UFRPE) e Especialista em Tecnologia Ambiental e Sustentabilidade nos Territórios Semiáridos (IF Sertão-PE). Técnico da Secretaria de Produção Rural, Recursos Hídricos e Meio Ambiente. Ouricuri/PE. E-mail: danilodiegos@hotmail.com 


\section{INTRODUÇÃO}

As áreas verdes desempenham funções de melhorias do ambiente urbano e da qualidade de vida da população. Neste sentido, os vegetais contribuem na manutenção das condições microclimáticas, pois suas folhas evaporam grandes volumes de água, contribuindo assim para redução da temperatura por meio desse eficiente mecanismo fisiológico. Mediante esse processo fisiológico, as plantas proporcionam temperaturas mais amenas, corroborando o efeito das árvores na melhoria microclimática dos ambientes, e em se tratando do ambiente urbano, tal fator contribui para a qualidade de vida dos habitantes (PINHEIRO; SOUZA, 2017).

Os parques urbanos como áreas verdes são espaços com presença de vegetação, no qual destacam-se como pontos turísticos, paisagísticos e ambientais. De maneira geral, os parques urbanos destacam-se como unidades urbanísticas essenciais para a vida nos ambientes urbanos. Além de grande área física, a cobertura vegetal é uma característica notável nestes espaços, sendo um dos principais componentes de grande relevância na formação da paisagem local (SILVA, MEUNIER; FREITAS, 2007). Para tal, o monitoramento da vegetação para fins de planejamento é essencial para o direcionamento de ações futuras, como escolha de espécies adequadas, implantação e manejo correto.

A falta de planejamento na implantação e na manutenção da arborização urbana é evidenciada em inúmeras cidades brasileiras, ocasionando diversos problemas (ALMEIDA; RONDON NETO, 2010), tais como o uso excessivo de espécies exóticas (BIONDI; MACEDO, 2008).

Portanto, o conhecimento da vegetação pode contribuir para a realização de projetos futuros de implantação de novas áreas verdes ou, ainda, para promover possíveis adequações, em caso de necessidade de substituição de indivíduos (SOUZA et al., 2011).

Deste modo, a análise da composição florística arbórea de uma cidade tem como finalidade quantificar o número de indivíduos e identificar a procedência das espécies, possibilitando também determinar a diversidade de espécies (LIMA NETO et al., 2016). Estudos de diversidade, distribuição das espécies, densidade de árvores no ambiente urbano auxiliam no monitoramento ecológico e ambiental (NAGENDRA; GOPAL, 2010). Portanto, faz-se necessário o monitoramento da cobertura vegetal.

O presente trabalho objetivou, por meio de levantamento florístico, verificar a diversidade e composição de espécies da comunidade arbórea do Parque Municipal Josepha Coelho, Petrolina-PE, visando contribuir para o planejamento da arborização do município, no qual o conhecimento da vegetação local é de fundamental importância para o estabelecimento de políticas públicas ambientais. 


\section{MATERIAL E MÉTODOS}

\section{Área de estudo}

O município de Petrolina localiza-se no sertão pernambucano e tem uma população estimada no ano de 2017 de 343.219 habitantes. Possui uma área territorial de $4.561,874 \mathrm{Km}^{2}$ (IBGE, 2017), sendo o maior município em extensão territorial do estado de Pernambuco. 0 território municipal tem a vegetação da Caatinga como cobertura florística natural.

O estudo foi realizado no Parque Municipal Josepha Coelho, localizado na área central urbana do município de Petrolina-PE (Figura 1).

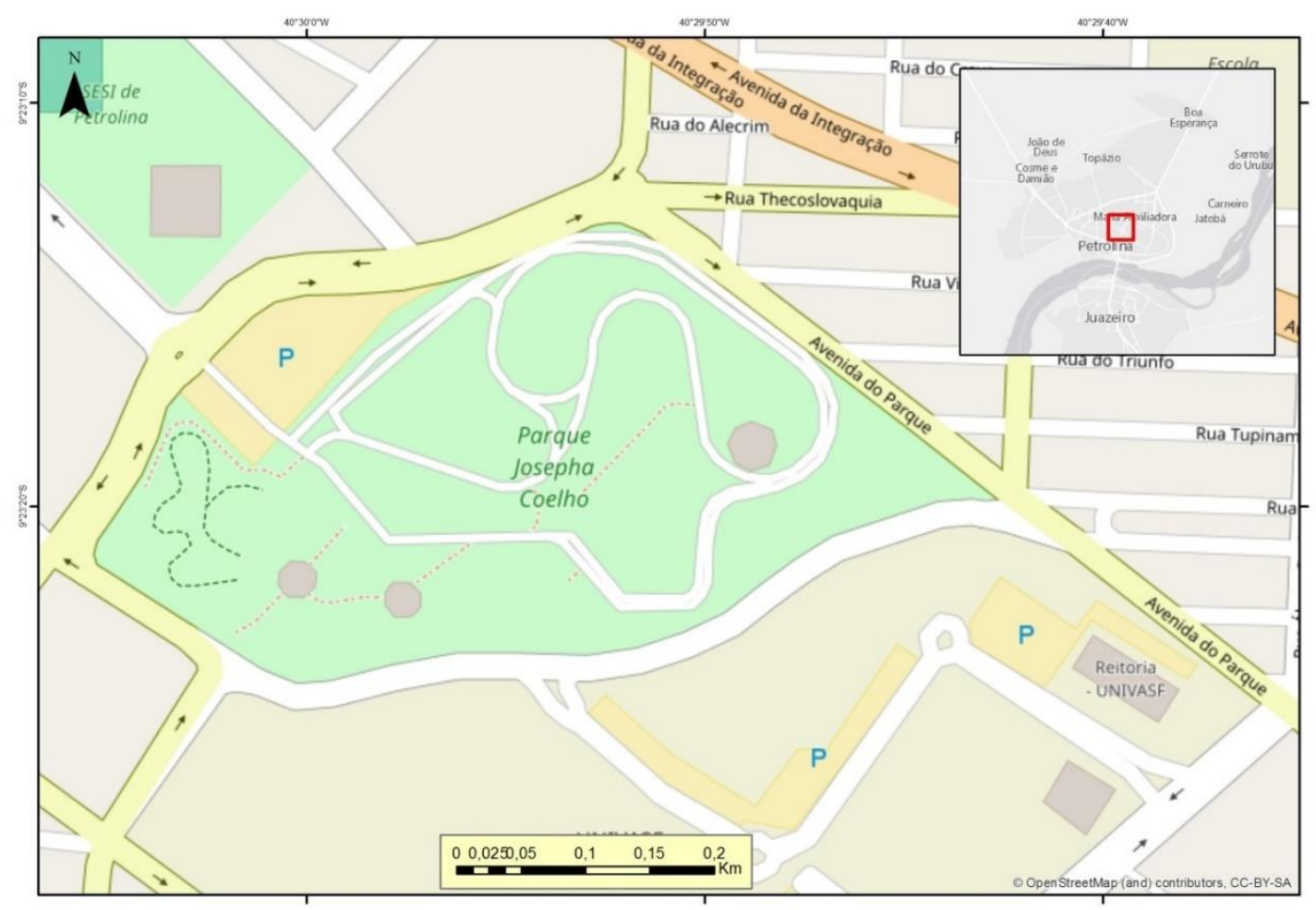

Figura 1. Localização geográfica do Parque Municipal Josepha Coelho, Petrolina-PE

Figure 1. Geographic location of Josepha Coelho Municipal Park, Petrolina-PE

O Parque Municipal Josepha Coelho, construído no começo da década de 90, perfaz uma área total de 152.016,425 metros quadrados. Destaca-se como ponto turístico, paisagístico, ambiental e é um dos pontos simbólicos da cidade. O local possui quadras poliesportivas, campo de futebol society, arenas de exposição artística, pista de skate, ciclovia, pista de caminhada, parque infantil, banheiros, etc. É um dos locais mais procurados pela comunidade, sendo a maior área verde situada no centro da cidade. São praticadas diversas atividades no local, como atividades esportivas, culturais, de lazer, recreação, educativas, dentre outras. 
Historicamente, a vegetação existente no parque foi implantada pelo poder público municipal, no qual é o responsável pela sua administração.

\section{Procedimento metodológico}

O levantamento quantitativo das espécies arbóreas foi feito por meio de visitas de campo. Para tanto, realizou-se o inventário por enumeração total (100\%), ou seja, o censo arbóreo, no qual identificou-se todos os indivíduos arbóreos com altura a partir de 3 metros. Os dados foram anotados em uma planilha. O estudo ocorreu no período de novembro de 2016 a janeiro de 2017.

A frequência relativa de cada espécie foi calculada pela razão entre o número de indivíduos da espécie e o número total de espécimes, multiplicada por 100.

As espécies arbóreas também foram identificadas e classificadas quanto à origem (nativas do Brasil ou exóticas), por meio de consultas bibliográficas especializadas, além de pesquisa ao banco de dados de herbários virtuais, como o Herbário Vale do São Francisco (HVASF), da Universidade Federal do Vale do São Francisco (UNIVASF).

\section{RESULTADOS E DISCUSSÃO}

$\mathrm{Na}$ análise da vegetação arbórea do Parque Municipal Josepha Coelho, constatou-se que sua composição florística é formada por 757 indivíduos distribuídos em 28 espécies, pertencentes a 10 famílias botânicas (Tabela 1).

As famílias botânicas mais representativas foram Fabaceae, com dez espécies, o que corresponde a $35,71 \%$ do total de espécies, seguida por Anacardiaceae, apresentando seis espécies (21,42\%), Arecaceae representada por quatro espécies (14,28\%) e Bignoniaceae com duas espécies (7,14\%). As demais famílias possuem representatividade abaixo de 3,6\%, apresentando apenas uma espécie (Figura 2).

A família Fabaceae foi a mais representativa na área de estudo, e isso pode ser explicado devido à grande quantidade de indivíduos que a família apresenta, pois segundo Judd et al. (2009), é a terceira maior família de angiospermas do mundo, com grande distribuição geográfica. No Bioma Caatinga, é também uma das famílias mais representativas (GIULIETTI et al., 2002), o que pode ser explicado pelo maior uso dessas espécies na arborização do parque, além disso, muitos indivíduos dessa família apresentam uma boa estrutura de copa pra arborização de parques. 
Tabela 1. Espécies arbóreas encontradas no Parque Municipal Josepha Coelho, Petrolina-PE

Table 1. Species found in the arboreal component of Josepha Coelho Municipal Park, Petrolina-PE

\begin{tabular}{|c|c|c|c|c|}
\hline $\begin{array}{l}\text { FAMÍLIA BOTÂNICA } \\
\text { NOME CIENTÍFICO }\end{array}$ & $\begin{array}{c}\text { NOME } \\
\text { POPULAR }\end{array}$ & ORIGEM & $\begin{array}{l}\text { QUANTI } \\
\text { DADE }\end{array}$ & $\begin{array}{c}\text { FREQ. } \\
(\%)\end{array}$ \\
\hline \multicolumn{5}{|l|}{ ANACARDIACEAE } \\
\hline Anacardium occidentale L. & Cajueiro & Nativa (Mata Atlântica) & 5 & 0,66 \\
\hline Mangifera indica L. & Mangueira & Exótica & 6 & 0,79 \\
\hline Myracrodruon urundeuva Fr. All. & Aroeira & Nativa (Caatinga) & 22 & 2,9 \\
\hline Schinopsis brasiliensis Engl. & Baraúna & Nativa (Caatinga) & 1 & 0,13 \\
\hline Spondias purpurea L. & Seriguela & Exótica & 2 & 0,26 \\
\hline Spondias tuberosa Arruda & Umbuzeiro & Nativa (Caatinga) & 5 & 0,66 \\
\hline \multicolumn{5}{|l|}{ ARECACEAE } \\
\hline Acrocomia aculeata (Jacq.) Lodd. ex Mart. & Macaúba & Nativa (Cerrado) & 1 & 0,13 \\
\hline Cocos nucifera L. & Coqueiro & Exótica & 66 & 8,71 \\
\hline Copernicia prunifera (Miller) H.E. Moore & Carnaubeira & Nativa (Caatinga) & 2 & 0,26 \\
\hline Phoenix dactylifera L. & Tamareira & Exótica & 77 & 10,17 \\
\hline \multicolumn{5}{|l|}{ BIGNONIACEAE } \\
\hline Handroanthus sp. & Ipê-rosa & Nativa (Caatinga) & 2 & 0,26 \\
\hline Tabebuia aurea (Manso) Benth. \& Hook. f. ex S. & Caraibeira & Nativa (Caatinga) & 80 & 10,56 \\
\hline \multicolumn{5}{|l|}{ CHRYSOBALANACEAE } \\
\hline Licania tomentosa (Benth.) Fritsch & Oiti & Nativa (Mata Atlântica) & 27 & 3,56 \\
\hline \multicolumn{5}{|l|}{ COMBRETACEAE } \\
\hline Terminalia catappa L. & Castanhola & Exótica & 4 & 0,52 \\
\hline \multicolumn{5}{|l|}{ FABACEAE } \\
\hline Adenanthera pavonina $\mathrm{L}$. & Carolina & Exótica & 35 & 4,62 \\
\hline Libidibia ferrea (Mart. ex Tul.) L.P. Queiroz & Pau-ferro & Nativa (Caatinga) & 17 & 2,24 \\
\hline Delonix regia (Bojer ex Hook.) Raf. & Flamboyant & Exótica & 55 & 7,26 \\
\hline $\begin{array}{l}\text { Paubrasilia echinata (Lam.) Gagnon, H.C. } \\
\text { Lima \& G.P. Lewis }\end{array}$ & Pau-brasil & Nativa (Mata Atlântica) & 100 & 13,21 \\
\hline Enterolobium contortisiliquum (Vell.) Morong. & Tamboril & Nativa (Caatinga) & 14 & 1,85 \\
\hline Erythrina velutina Willd. & Mulungu & Nativa (Caatinga) & 1 & 0,13 \\
\hline Leucaena leucocephala (Lam) de Wit. & Leucena & Exótica & 61 & 8,05 \\
\hline Poincianella pyramidalis (Tul.) L. P. Queiroz & Catingueira & Nativa (Caatinga) & 1 & 0,13 \\
\hline Prosopis juliflora (Sw.) DC. & Algarobeira & Exótica & 12 & 1,58 \\
\hline Senna siamea (Lam.) H.S. Irwin \& Barneby & Cássia & Exótica & 1 & 0,13 \\
\hline \multicolumn{5}{|l|}{ MELIACEAE } \\
\hline Azadirachta indica A. Juss & Neem & Exótica & 126 & 16,64 \\
\hline \multicolumn{5}{|l|}{ MORACEAE } \\
\hline Ficus benjamina L. & Ficus & Exótica & 1 & 0,13 \\
\hline \multicolumn{5}{|l|}{ MYRTACEAE } \\
\hline Eucalyptus sp. & Eucalipto & Exótica & 5 & 0,66 \\
\hline \multicolumn{5}{|l|}{ RHAMNACEAE } \\
\hline Ziziphus joazeiro Mart. & Juazeiro & Nativa (Caatinga) & 28 & 3,69 \\
\hline \multicolumn{3}{|l|}{ Total } & 757 & $100 \%$ \\
\hline
\end{tabular}




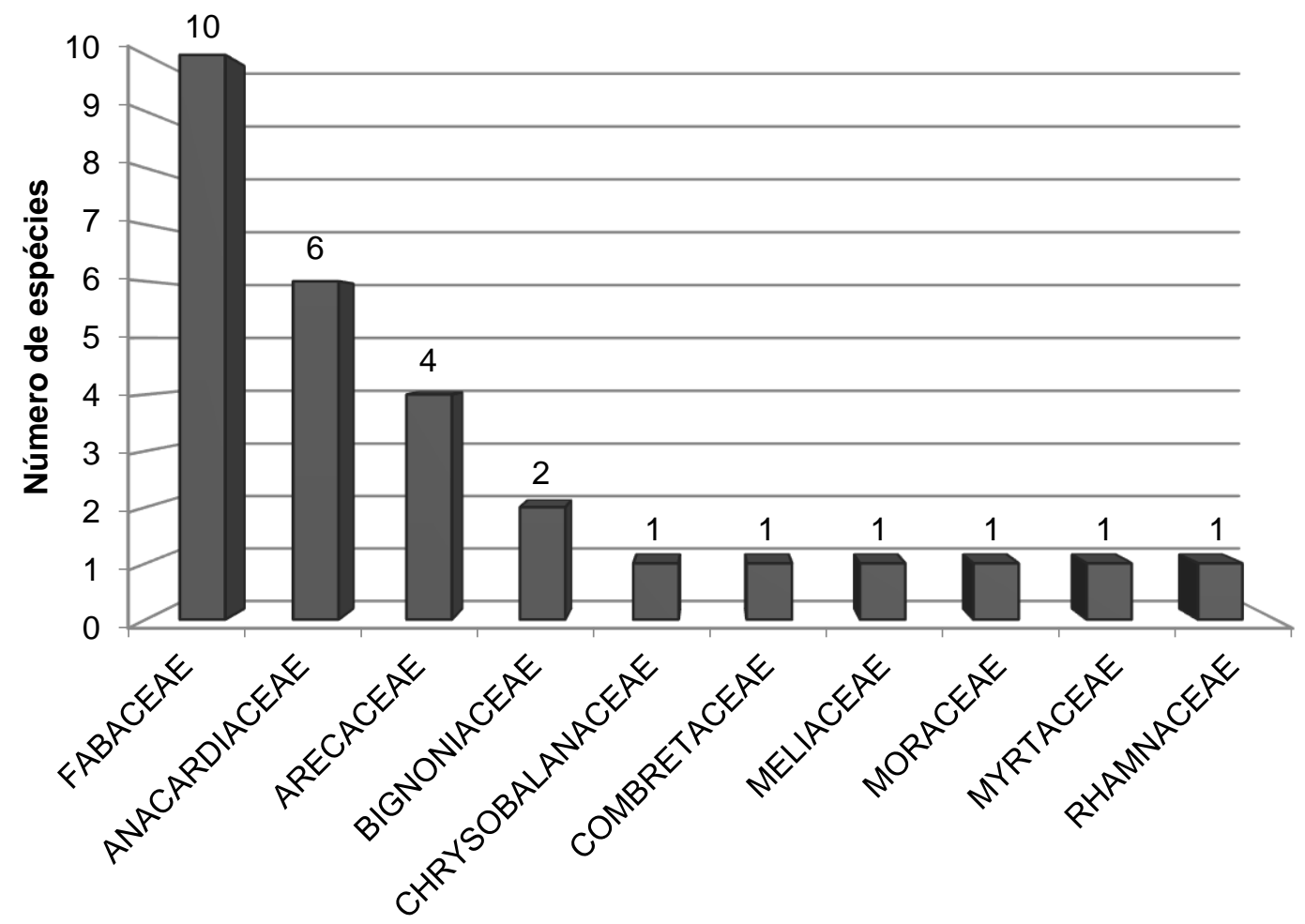

Famílias

Figura 2. Número de espécies e suas respectivas famílias botânicas Figure 2. Number of species and their botanical families

O levantamento indicou ainda que 50,59\% das espécies eram nativas brasileiras e 49,41\% exóticas do Brasil, o que significa que o número de espécies exóticas é bastante pronunciado. Isso pode ser explicado pela introdução de espécies exóticas com potencial ornamental, porém com pouca preocupação com a valorização da flora local. Tal fator pode acarretar em danos ao meio ambiente, como também pode comprometer as gerações atuais e futuras de conhecer as espécies nativas da Caatinga. Diante disso, a grande presença de espécies exóticas indica que é necessário a conservação da vegetação nativa do parque, em especial das espécies nativas da Caatinga.

É importante salientar que algumas espécies nativas da Caatinga encontradas no parque estão ameaçadas de extinção e seria interessante a ampliação do número de indivíduos, como as espécies Schinopsis brasiliensis Engl. (baraúna) e Myracrodruon urundeuva Fr. All. (aroeira), além de outras nativas que poderiam ser introduzidas.

$\mathrm{Na}$ maioria dos municípios brasileiros é bastante comum encontrar alta frequência de espécies exóticas (BIONDI, 2011). A introdução de espécies exóticas no ambiente urbano é preocupante e proveniente de um mau planejamento da arborização e muitas vezes pelo desconhecimento da legislação (HOPPEN et al., 2014), como também pelo desconhecimento 
dos problemas ambientais ocasionados por essas espécies. Além disso, essa prática tem como consequência a desvalorização da flora nativa, em especial da flora local.

Das espécies exóticas identificadas, aquelas que apresentaram maior abundância foram Azadirachta indica A. Juss (neem) apresentando 126 indivíduos (16,64\%), Phoenix dactylifera L. (tamareira) com 77 indivíduos (10,17\%), Cocos nucifera L. (coqueiro) com 66 indivíduos (8,71\%), Leucaena leucocephala (Lam) de Wit. (leucena) com 61 indivíduos (8,05\%), Delonix regia (Bojer ex Hook.) Raf. (flamboyant) com 55 indivíduos (7,26\%) e Adenanthera pavonina L. (carolina) com 35 indivíduos (4,62\%) (Figura 3).

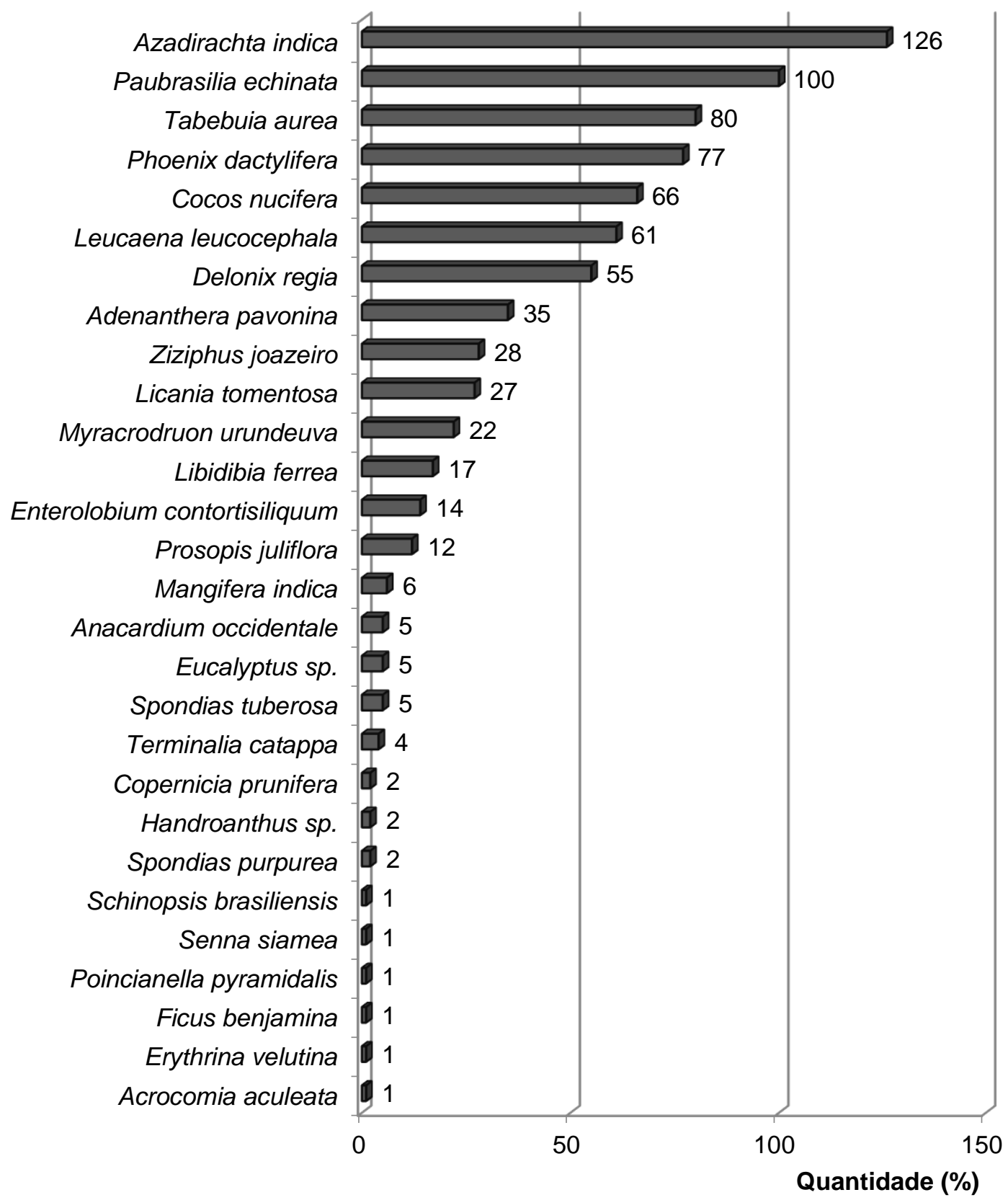

Figura 3. Número de espécies arbóreas encontradas no Parque Municipal Josepha Coelho, Petrolina-PE Figure 3. Number of tree species found in Josepha Coelho Municipal Park, Petrolina-PE 
Brito et al. (2012) observaram o grande número de espécies exóticas nas praças públicas do município de Bom Jesus-PI. Das espécies identificadas, Azadirachta indica se destacou com $29 \%$ de abundância. Os autores afirmam ainda que isso pode ser explicado pela falta de planejamento da arborização urbana ou pela dificuldade na obtenção de mudas de espécies da flora regional, razão pela qual a maioria das espécies utilizadas nas praças são exóticas.

Crispim et al. (2014) também encontraram alta frequência de espécies exóticas na arborização do centro da cidade de Pombal-PB. A. indica apresentou 42,1\% de frequência e Ficus benjamina L. (ficus) 25,2\%. Já Morais e Machado (2014) destacaram a espécie Azadirachta indica como a mais representativa, apresentando 437 indivíduos ou 18,84\%, no município de Timon, no Maranhão. Zea et al. (2015) constataram percentuais elevados de A. indica, com 864 indivíduos, correspondendo a $69,2 \%$ do total de indivíduos inventariados em Santa Helena, Paraíba. O que corrobora mais uma vez o intenso uso de espécies exóticas na arborização urbana, pois espécies exóticas causadoras de impactos ambientais podem interferir nos processos ecológicos da paisagem urbana, como também descaracteriza o ecossistema natural local.

A. indica é uma planta de origem asiática, a qual produz uma variedade de substâncias com atividades biológicas sobre insetos, particularmente alterações no seu desenvolvimento e comportamento (MARTINEZ; VAN EMDEN, 1999). No Brasil está sendo amplamente disseminada por meio da arborização, e isso se deve principalmente ao rápido crescimento e desenvolvimento nas regiões áridas. No entanto, embora apresente crescimento acelerado e bom sombreamento, poderá contribuir para alterações ecológicas significativas no ambiente (VALE et al., 2011).

Outra preocupação relacionada ao cultivo de espécies exóticas é que algumas espécies como Prosopis juliflora (Sw.) DC. (algarobeira), Azadirachta indica e Leucaena leucocephala (Lam) de Wit. (leucena), são consideradas espécies invasoras (INSTITUTO HÓRUS, 2016), o que facilitaria a propagação dessas espécies nos ambientes põe em risco a integridade de espécies nativas. O fenômeno de substituição de espécies nativas por exóticas é considerado uma ameaça à biodiversidade (VAN WILGEN et al., 2008).

Sousa, Figuêiredo e Braga (2013) também observaram que 51,75\% dos indivíduos pertenciam à espécie exótica $A$. indica no Distrito de Rafael Arruda, Sobral-CE. Estes verificaram uma alta frequência de espécies exóticas na localidade. Os efeitos decorrentes da dominância da espécie exótica ( $A$. indica) em diversos ambientes urbanos podem ser explicados pelo imediatismo de resultados, pois a espécie apresenta crescimento rápido e, como consequência, proporciona sombreamento a curto prazo.

A elevada predominância de uma mesma espécie é uma condição desfavorável, uma vez que podem ocorrer problemas fitossanitários, pois a baixa diversidade pode aumentar a 
ocorrência de pragas e doenças (HAAS et al., 2011; KENDAL; DOBBS; LOHRC, 2014). A. indica, por exemplo, além de não ser uma espécie indicada, como já foi supracitado, perfaz 16,64\% do total de espécies do Parque Municipal Josepha Coelho.

Segundo Silva, Meunier e Freitas (2007), ao se optar por espécies exóticas, perde-se a oportunidade de ensinar e promover a aprendizagem da comunidade sobre as plantas nativas e contribuir para o desenvolvimento de atitudes necessárias à conservação da biodiversidade local.

A prática do uso excessivo de espécies exóticas na arborização urbana tem gerado uma descaracterização da flora nativa. Além disso, algumas espécies exóticas podem gerar impactos sobre a biodiversidade local. O recomendável seria a utilização de plantas nativas locais.

Oliveira et al. (2013) citam os benefícios na utilização de espécies nativas na arborização, como a contribuição para a conservação da biodiversidade local. Além disso, a utilização de espécies nativas na arborização urbana é uma forma de valorização da flora brasileira, pois segundo Silva (2008), promove a identidade arbórea das cidades.

\section{CONCLUSÕES}

O estudo revelou a presença de grande quantidade de espécies exóticas, com destaque para Azadirachta indica, na qual foi a espécie que apresentou maior frequência, o que tem se tornado comum em muitas cidades e pode acarretar danos ao meio ambiente, como a perda da biodiversidade local, alterações nos processos ecológicos naturais, dentre outros. Deve-se priorizar a utilização de espécies nativas da Caatinga, com intuito de promover a diversidade adequada no local, tais como a conservação e valorização da flora local, além de melhoria nos processos ecológicos naturais. Sugere-se a substituição gradual do neem ( $A$. indica) por espécies nativas e mais adequadas aos ambientes urbanos.

A grande presença de espécies exóticas na arborização urbana retrata uma ausência de preocupação com a conservação da vegetação nativa, como também o desconhecimento dos impactos ambientais causados por essas plantas exóticas. Sendo assim, torna-se necessário a elaboração de um plano municipal de arborização com plantio de espécies nativas para uma gestão ambiental eficiente. 


\section{REFERÊNCIAS}

ALMEIDA, D. N.; RONDON NETO, R. M. Análise da arborização urbana de três cidades da região norte do Estado de Mato Grosso. Acta Amazonica, Manaus, v. 40, n. 4, p. 647-656, 2010.

BIONDI, D. Introdução de espécies na arborização de ruas. In: BIONDI, D.; LIMA NETO, E. M. (Org.). Pesquisas em arborização de ruas. Curitiba: O Autor, 2011. p. 9-28.

BIONDI, D.; MACEDO, J. H. P. Plantas invasoras encontradas na área urbana de Curitiba - PR. Floresta, Curitiba, v. 38, n.1, p. 129-144, 2008.

BRITO, D. R. S.; RAABE, J.; SOUSA, W. C.; MELO, R. R.; PEDROSA, T. D. Diagnóstico da arborização das praças pública no município de Bom Jesus, Piauí. Scientia Plena, Aracajú, v. 8, n. 4, p. 01-06, 2012.

CRISPIM, D. L.; SILVA, M. A.; CHAVESS, A. D. C. G.; ALMEIDA, R. R. P.; FREITAS, A. J. F. Diagnóstico da arborização urbana do centro da cidade de Pombal-PB. Revista Verde de Agroecologia e Desenvolvimento Sustentável, Campina Grande, v. 9, n. 1, p. 191-196, 2014.

GIULIETTI, A. M.; HARLEY, R. M.; QUEIROZ, L. P.; BARBOSA, M. R. V.; BOCAGE, A. L.; FIGUEIREDO, M. A. Espécies endêmicas da Caatinga. In: SAMPAIO, E. V. S. B.; GIULIETTI, A. M.; VIRGíNIO, J.; GAMARRA-ROJAS, C. F. L. (Eds.) Vegetação e Flora da Caatinga. Recife, Associação Plantas do Nordeste, 2002. p. 103-105.

HAAS, S. E.; HOOTEN, M. B.; RIZZO, D. M.; MEENTEMEYER, R. K. Forest species diversity reduces disease risk in a generalist plant pathogen invasion. Ecology Letters, Oxford, v. 14, n. 11, p. 1108-1116, 2011.

HOPPEN, M. I.; DIVENSI, H. F.; RIBEIRO, R. F.; CAXAMBÚ, M. G. Espécies exóticas na arborização de vias públicas no município de Farol, PR, Brasil. Revista da Sociedade Brasileira de Arborização Urbana, Piracicaba, v. 9, n. 3, p. 173-186, 2014.

INSTITUTO BRASILEIRO DE GEOGRAFIA E ESTATÍSTICA (IBGE). Cidades. Disponível em: <http://cidades.ibge.gov.br/xtras/perfil.php?codmun=261110>. Acesso em: 13 set. 2017.

INSTITUTO HÓRUS DE DESENVOLVIMENTO E CONSERVAÇÃO AMBIENTAL. Base de dados de espécies exóticas invasoras. Disponível em: <www.institutohorus.org.br $>$. Acesso em: 22 nov. 2016.

JUDD, W. S.; CAMPBELL, C. S.; KELLOGG, E. A.; STEVENS, P. F.; DONOGHUE M. J.; Tradução: André Olmos Simões. Sistemática vegetal: um enfoque filogenético. 3. ed. Porto Alegre: Artmed, 2009. 632p.

KENDAL, D.; DOBBS, C.; LOHRC, V. I. Global patterns of diversity in the urban forest: Is there evidence to support the 10/20/30 rule? Urban Forestry \& Urban Greening, Columbia, v. 13, p. 411-417, 2014.

LIMA NETO, E. M.; BIONDI, D.; SILVA, F. L. R.; PINHEIRO, F. A. P. Análise da composição florística de Boa Vista-RR: subsídio para a gestão da arborização de ruas. Revista da Sociedade Brasileira de Arborização Urbana, Piracicaba, v. 11, n. 1, p. 58-72, 2016.

MARTINEZ, S. S.; VAN EMDEN, H. F. Sublethal concentrations of azadirachtin affect food intake, conversion efficiency and feeding behaviour of Spodoptera littoralis (Lepidoptera: Noctuidae).

Bulíetin of Entomological Research, Brisbane, v. 89, n. 1, p. 65-71, 1999. 
MORAIS, L. A.; MACHADO, R. R. B. A arborização urbana do município de Timon/MA: inventário, diversidade e diagnóstico quali-quantitativo. Revista da Sociedade Brasileira de Arborização Urbana, Piracicaba, v. 9, n. 4, p 80-98, 2014.

NAGENDRA, H.; GOPAL, D. Street trees in Bangalore: Density, diversity, composition and distribution. Urban Forestry \& Urban Greening, Amsterdam, v. 9, p. 129-137, 2010.

OLIVEIRA, M. D.; PERETTI, C.; BUDKE, J. C.; SANTOS, S. C. D.; CORAZZA, T.; GOMES, S.; QUADROS, F. R. D.; DECIAN, V. S.; ZANIN, M. E. Reflexos da evolução urbana sobre a arborização em Erechim, Sul do Brasil. Revista da Sociedade Brasileira de Arborização Urbana, Piracicaba, v. 8, n. 2, p. 86-103, 2013.

PINHEIRO, C. R.; SOUZA, D. D. A importância da arborização nas cidades e sua influência no microclima. Revista Gestão e Sustentabilidade Ambiental, Florianópolis, v. 6, n. 1, p. 67-82, 2017.

SILVA, L. M. Reflexões sobre a identidade arbórea das cidades. Revista da Sociedade Brasileira de Arborização Urbana, Piracicaba, v. 3, n. 3, p. 65-71, 2008.

SILVA, L. R.; MEUNIER, I. M. J.; FREITAS, A. M. M. Riqueza e densidade de árvores, arvoretas e palmeiras em parques urbanos de Recife, Pernambuco, Brasil. Revista da Sociedade Brasileira de Arborização Urbana, Piracicaba, v. 2, n. 4, p. 34-49, 2007.

SOUSA, L. M.; FIGUEIRÊDO, M. F.; BRAGA, P. E. T. Levantamento quali-quantitativo da arborização urbana do distrito de Rafael Arruda, Sobral, CE. Revista da Sociedade Brasileira de Arborização Urbana, Piracicaba, v. 8, n. 3, p. 118-129, 2013.

SOUZA, A. L.; FERREIRA, R. A.; MELLO, A. A.; PLÁCIDO, D. R.; SANTOS, C. Z. A.; GRAÇA, D. A. S.; ALMEIDA JÚNIOR, P. P.; BARRETTO, S. S. B.; DANTAS, J. D. M.; PAULA, J. W. A.; SILVA, T. L.; GOMES, L. P. S. Diagnóstico quantitativo e qualitativo da arborização das praças de Aracaju, SE. Revista Árvore, Viçosa, v. 35, n. 6, p. 1253-1263, 2011.

VALE, N. F. L.; SOUSA, G. S.; MATA, M. F.; BRAGA, P. E. T. Inventário da arborização do parque da cidade do município de Sobral, Ceará. Revista da Sociedade Brasileira de Arborização Urbana, Piracicaba, v. 6, n. 4, p. 145-157, 2011.

VAN WILGEN, B. W.; REYERS, B.; LE MAITRE, D. C.; RICHARDSON, D. M.; SCHONEGEVEL, $\mathrm{L}$. A biome-scale assessment of the impact of invasive alien plants on ecosystem services in South Africa. Journal of Environmental Management, Sint-Katelijne-Waver, v. 89, n. 4, p. 336349, 2008.

ZEA, C. J. D.; BARROSO, R. F.; SOUTO, P. C.; SOUTO J. S. Levantamento e diversidade da arborização urbana de Santa Helena, no semiárido da Paraíba. Agropecuária Científica no Semiárido, Campina Grande, v. 11, n. 4, p. 54-62, 2015. 